\title{
Study of Morphological Nature of Coronavirus: Causes and Prevention
}

\author{
Meetkamal $^{1 *}$ (D) and R.K. Dwivedi² (i) \\ ${ }^{1}$ Department of Chemistry, Christ Church College, Kanpur - 208 001, India. \\ ${ }^{2}$ Department of Physics, Christ Church College, Kanpur - 208 001, India.
}

\begin{abstract}
The emergence of an unusual Corona virus (COVID-19) flu pandemic starting in China in December 2019 , spreading all around the globe is a major threat to public health. The investigations have shown this virus originated from a seafood market in Wuhan. However, the unavailability of medicines for the new disease is a big challenge all around. An attempt has been made in the present article to familiarise about the morphology of the virus. The study of effect of $\mathrm{pH}$, temperature and relative humidity is also depicted. Various preventive measures have also been discussed. The natural dietary measures suggested in the paper would be very beneficial to improve and boost the immunity of the mankind.
\end{abstract}

Keywords: Coronavirus, Relative Humidity, Hand sanitizer, Immunity

\footnotetext{
*Correspondence: meetk_dwi@yahoo.co.in

(Received: April 13, 2020; accepted: May 28, 2020)

Citation: Meetkamal, Dwivedi RK. Study of Morphological Nature of Coronavirus: Causes and Prevention. J Pure App/ Microbiol. 2020;14(suppl 1):963-970. doi: 10.22207/JPAM.14.SPL1.34

C The Author(s) 2020. Open Access. This article is distributed under the terms of the Creative Commons Attribution 4.0 International License which permits unrestricted use, sharing, distribution, and reproduction in any medium, provided you give appropriate credit to the original author(s) and the source, provide a link to the Creative Commons license, and indicate if changes were made.
} 


\section{INTRODUCTION}

Last few months have seen the emergence of an unusual Corona virus flu pandemic starting in China and then spreading like anything all around the globe. This virus has never been detected in humans earlier and therefore it is considered as one of the most dangerous viruses transmitted from the animals to humans ${ }^{1}$ spreading all over the world in a drastic manner. With the outbreak of unknown pneumonia in Wuhan (China) in December 2019, a new corona virus, Severe Acute Respiratory Syndrome Coronavirus 2 (SARS-CoV-2) aroused the attention of the entire world. The current outbreak of infections with SARS-CoV-2 is termed Corona virus Disease 2019 (COVID-19). The World Health Organization (WHO) has declared COVID-19 in China as a public health emergency of international concern. All the three of these emerging infectious diseases leading to a global spread are caused by $\beta$-coronaviruses which is one of the four genera of corona viruses (sub family orthocoronavirinae, family coronaviridae). Although coronaviruses usually infect the upper or lower respiratory tract, viral shedding in plasma or serum is common. In the past also, two other coronavirus infections SARS in 2002-2003 and Middle East Respiratory Syndrome (MERS) in 2012-both have caused severe respiratory syndrome in humans ${ }^{2}$. The recent COVID-19 pandemic is a major source of disaster in the $21^{\text {th }}$ century as there is no vaccine or medicine available till date to prevent and cure it. Therefore, it is essential to understand several aspects of COVID-19 so as to aware the community about various aspects of this virus and helping us to save our lives.

Morphological Nature of CoV

A single-stranded positive largest RNA genome covered by a sheath of spherical or rod shaped or coccoid shape structure with projections of glycoprotein of $80-120 \mathrm{~nm}$ diameter on its surface is characterized as coronavirus in the literature ${ }^{3,4}$. The RNA genome of CoV is packed in the nucleocapsid protein and further covered with envelope. CoV attaches to the target cells with the help of spike protein-host cell protein interaction (angiotensin converting enzyme-2 [ACE-2] interaction in SARS-CoV 5 and dipeptidyl peptidase-4 [DPP-4] in MERS-CoV) ${ }^{6}$. The detailed structure is given in Fig. $1 .{ }^{32}$
The virus now recognises the receptor cell and it releases the virus genome with its nucleocapsid into the cytoplasm of the host cells. ORF1a and ORF1b genes contained in the genome of the virus produces two PPs that are ppla and $\mathrm{pp} 1 \mathrm{~b}^{7}$, which both undergoes their own translation process ${ }^{8}$ to form replication transcription complex by taking command over host ribosomes. This phenomenon is called processing of PP by protease, which produces 16 NSPs. All NSPs have their own specific functions such as NSP1and NSP2 suppresses host gene expression,NSP3 forms a multi-domain, NSP5, a M protease has role in replication ${ }^{9}$, NSP4 and NSP6 are transmembrane (TM) proteins ${ }^{10}$, NSP7 and NSP8 which act as a primase ${ }^{7}$, NSP9 - a RNA-binding protein, the dimeric form of which is very important for viral infection ${ }^{11}$. The best alternative to overcome CoV infection ${ }^{10}$ is to cause hindrance in the dimerization of NSP9 ${ }^{10}$. A cofactor for the activation of the replicative enzyme is done by NSP10 ${ }^{12}$. RNAdependent RNA polymerase activity is shown by NSP12, helicase activity by NSP13, exoribonuclease activity by NSP14, endoribonuclease activity by NSP15 and NSP16 has methyltransferase activity ${ }^{9}$. It means that all NSPs play vital role in replication and transcription ${ }^{9}$.

$M, E$ and $S$ are synthesized proteins which enter into the endoplasmic reticulum forming (ER)Golgi intermediate compartment (ERGIC) complex and make the structure of viral envelope ${ }^{13}$. On the other hand, the replicated genome binds to $N$ protein and forms the ribonucleoprotein (RNP) complex. The outer cover is formed by the M, $\mathrm{E}$, and $\mathrm{S}$ proteins. Finally, the virus particle comes out of the ERGIC by making a bud-like structure ${ }^{14}$. These mature virions form a vesicle, which fuses with the plasma membrane and releases the virus particles into the extracellular region ${ }^{14,15}$. The life cycle of the virus is depicted in fig. 2. The SARS-CoV and MERS-COV cause a surge of pro-inflammatory cytokines and chemokines, which cause damage to lung tissue, deterioration of lung function, and then finally lung failure in some cases ${ }^{16}$.

A brief outline of the Angiotensinconverting enzyme 2 (ACE2) as a SARS-CoV-2 receptor: molecular mechanisms and potential therapeutic target is shown in the flowchart manner 
S Protein (virus) + ACE2 ENTRY STARTS Viral RNA

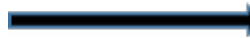

genome enters the host cell

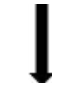

Protein starts translating SP \& NSP

(ORF1a \& ORF 1b) Translate

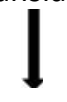

PP1a and pp1b polyproteins

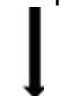

Cleaved by proteases [encoded by ORF1a] 16 non structural proteins(NSP 1-16)

Transcription, Replication,Translation S,M.E protein

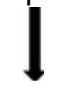

Structural protein undergoes Assembly and Budding ENTERS

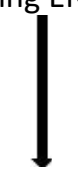

Endoplasmic Reticulum Forming ERGIC Complex forming Viral Envelope

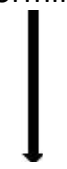

Virions are then released from the host cell By EXOCYTOSIS Releases

INFECTION SPREADS Into the extracellular region.

S: spike, E: envelope, M: membrane, $\mathrm{N}$ : nucleocapsid. PP: polyproteins, ORF: Open 16 reading frame, CoV: coronavirus, ERGIC: Endoplasmic reticulum golgi intermediate complex, pp: Polyprotein, SP: Structural protein, NSP: Nonstructural proteins, ACE2: Angiotensin converting enzyme 2
Nature of S-Protein is very important to understand Fig. $2{ }^{3}$

It is a clove shaped type protein ${ }^{3}$. It constitutes of three segments one in ectodomain (ED)region other in TM region and the last in intracellular domain which is referred as intracellular tail part ${ }^{11}$. The three S1 heads (S1 domain) bind the receptor and the membrane fusion subunit $\mathrm{S} 2$ are called the trimeric stalk on $C$ terminal together comprise the ED. The Spike protein gather in the trimeric form on the outer surface of the virion giving the appearance of the crown therefore it is called CoV. It plays a potential role in virus entry into the host ${ }^{4}$.

Effect of Temperature on COVID-19

Temperature and humidity on the earth surface are very important parameters affecting the behaviour and the spread of the viruses. Temperatures on one hand affect the immunity of the human body and on the other side it is capable of breaking the outer layer of the virus made of lipids ${ }^{17-19}$. Viruses may have temperature ranges where they can survive longer. It has been reported in the literature that SAR-COV-2 can survive upto 72 hours on hard plastic and stainless steel surface at temperature between $21-23^{\circ} \mathrm{C}$ and in relative humidity of $40 \%^{19}$. Transmissible Gastroenteritis Virus (TGEV) and Mouse Hepatitis Virus (MHV) viruses on stainless surface are reported to survive for 28 days at $4^{\circ} \mathrm{C}$, however, the inactivation was rapid at $20^{\circ} \mathrm{C}^{19}$. It is essential to investigate the duration of survival of COVID under different conditions and on different surfaces also. It will help to us to understand the pathways of disease transmission and improved response strategy accordingly. COVID-19 is a nanosized grease balls with weakest lipid bilayer. It has been found to stay active for 8-10 days on dry surface and survive in human body at $37^{\circ} \mathrm{C}$. Therefore, it is expected that COVID-19 may come to an end with increase in temperature in India in May-June 2020, however, a detailed investigations on the activation of COVID-19 on different surfaces under different ambient conditions such as temperature of the surroundings and humidity is required to fully understand the spread of this pandemic. In the meantime, it is advised to follow the guidelines of social distance, hand and respiratory hygiene etc. to avoid the infection. Taking lukewarm water, 
inhaling hot water steam and hot drinks several times a day might help to keep throat and nose away from the coronavirus. The transmission of an infectious disease requires that the pathogens can survive in the environment outside the host. Relative humidity ( $\mathrm{RH}$ ) is known to affect the survival of the some microorganisms in the environment. Most of the respiratory viruses including influenza, corona-viruses including severe acute respiratory syndrome-associated corona-virus which are lipid enveloped, are reported to survive longer at lower relative humidity $20-30 \%$. Temperature is one of the most important factor affecting virus survival as it can affect the state of viral proteins (including enzymes) and the virus genome (RNA or DNA). Viruses containing DNA are generally more stable than RNA viruses but high temperatures also affect DNA integrity. In general, the survival of the virus is found to decrease with increase in temperature.
Maintaining temperatures above $60^{\circ} \mathrm{C}$ for more than one hour is generally sufficient to inactivate most viruses, though it is very strongly dependent on the presence of surrounding organic material such as blood, faeces, mucus, saliva, etc. which will tend to insulate the virus against extreme environmental changes. Most of the airborne viruses will have been exhaled with a coating of saliva or mucus that will act as an organic barrier against environmental extremes. Higher temperatures for shorter times might be effective to inactivate viruses.

\section{Effect of $\mathrm{pH}$ on Coronavirus}

In order to understand the stability of different viruses, it is desirable to know the effect of $\mathrm{pH}$ along with temperature of the infectivity of virus ${ }^{18}$. Once entered into the host cell, the subsequent life cycle of SERS-CoV requires low $\mathrm{pH}$. Inhibitors of $\mathrm{pH}$-sensitive endosomal protease have been reported to block CoV infection. Several

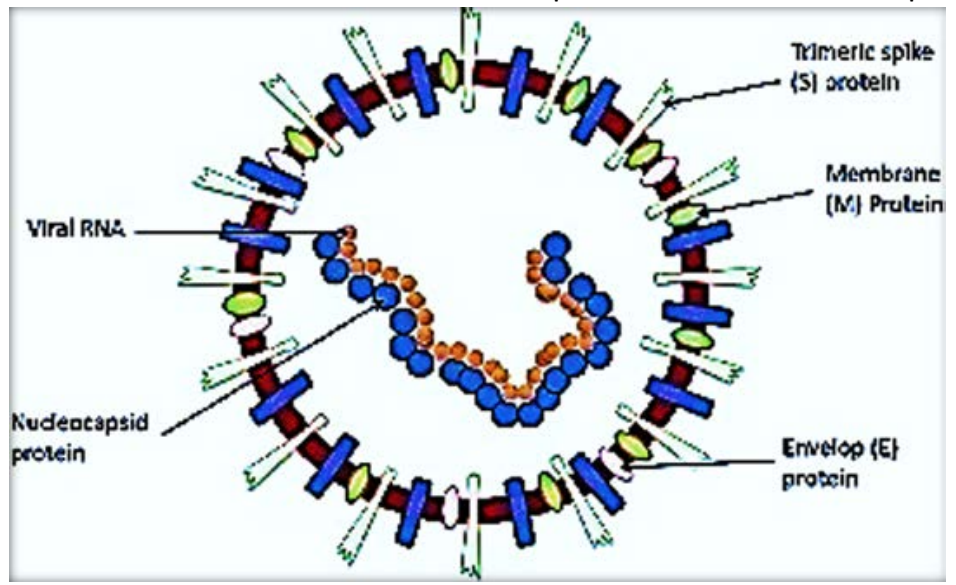

Fig. 1. Structure of Coronavirus

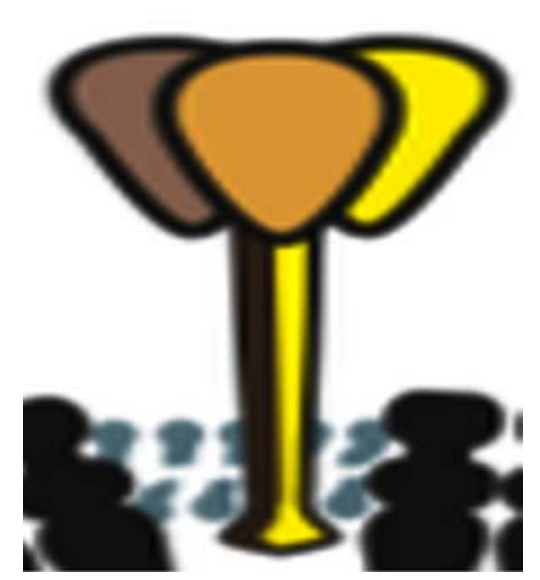

Fig. 2. Structure of S protein different small compounds and molecules have also been reported against virus infection. Amiodarone gets accumulated in the acidic organelles. Vacuoles on exposure to amiodarone shows alteration in intracellular organelles especially enlargement of late endosomes. In in-vitro environment, amiodarone inhibited coronavirus infection in Vero cells. At priori trypsin, cleavage of S protein is essential for a successful viral entry. The stability of human coronavirus 229E infectivity was reported maximum at $\mathrm{pH} 6.0$ when incubated at either 4 or $33^{\circ} \mathrm{C}$. However, the influence of $\mathrm{pH}$ was found more pronounced at $33^{\circ} \mathrm{C}$. Viral infectivity was completely lost after a 14-day incubation period at 22,33 , or $37^{\circ} \mathrm{C}$ but remained relatively constant 
at $4^{\circ} \mathrm{C}$ for the same length of time. Finally, the infectious titer did not show any significant reduction when subjected to 25 cycles of thawing and freezing. These studies will contribute to optimize virus growth and storage conditions, which will facilitate the molecular characterization of this important pathogen. The $\mathrm{pH}$ for corona virus family is claimed to vary from 5.5 to 8.5 . Professor Tanimola Akande of University of Ilorin in Western Nigeria told Africa Check recently that the new coronavirus does not have its own $\mathrm{pH}$. He said it survived well in an environment with a $\mathrm{pH}$ of about 6 and was unable to survive at a $\mathrm{pH}$ of 8 and above ${ }^{20}$. It has also been reported that the addition of ammonium chloride, which prevents acidification of the endosome, caused a dose-dependent reduction in viral entry through DC SIGN methods ${ }^{21}$. Chloroquine ${ }^{22}$ being an antimalarial drug has been found to increase the $\mathrm{pH}$ of endosome and thereby altering the terminal glycosylation of ACE2 which hinders the binding of virus and receptor.

Symptoms of COVID- 19 are common cold, running nose, dry cough, headache, breathing problem, fever (temperature $>100.4^{\circ} \mathrm{F}$ ), pneumonia, chest pain and pressure, diarrhoea, loss of taste and smell etc. ${ }^{23}$. An individual should immediately go for medical supervision if any of the symptoms prolong for more than 10 hours. Even one thing more has been studied that should be very much taken into consideration that COVID-19 patients might be infectious during an asymptomatic incubation period.

Dietary measures

In order to avoid CoVID-19 infection, it is advisable to boost up the immunity by taking care of the following in your daily diet. Studies suggest to take maximum intake of antioxidants, fiber, oils and acids that keeps the immune system healthy. Eat plenty and try to include as many different colors as you can, to ensure you benefit from the full range of bioactive compounds they contain. Olive oil ${ }^{24-25}$ has good antioxidant and antiviral properties and its use seems to be a good remedy for COVID-19 in the present situation. There are several naturopathy remedies which can be adapted like a strong tea made from concoction of ginger, star anise and unpasteurised honey is the natural home remedy for this. The virgin coconut oil and its derivatives are very effective against this virus. The food cooked in pure coldpressed coconut oil or even the raw coconut oil can act as antiviral in both humans and animals. Vitamin-C supplementation is also useful to boost the immune system. Vitamin-C rich foods such as amla, red peppers, yellow peppers and Vitamin $C$ supplements decrease the severity of the infection. Antiviral herbs are those herbs which are active against viral infections. They are an important part of natural and alternative medicine. Anti-viral herbs ${ }^{26-27}$ such as Oregano, Basil (Tulsi), Garlic, Ginger, Sage, Fennel, dried Thyme, Echinacea, Licorice etc. because of their medicinal qualities are great for our body immunity and can be used in teas or curries for respiratory health including mucous problems which can guard individuals from viral infections. Oregano ${ }^{28}$ is a popular herb from the mint family for its impressive medicinal quality. It is shown to exhibit antiviral activity against several viruses. Sacred Basil boosts the immunity which can help fight viral infections. Basil ${ }^{26}$ extract significantly protects and defends our body from viral infections according to the article published in U.S. National Institutes of Health's National Library of Medicine (NIH/NLM).Garlic ${ }^{30}$ is an anti-viral food par excellence. Its effectiveness against viruses has been published in NIH/NLM. It should be eaten raw to take advantage of its qualities. If one cooks it, chop it half an hour before, so that its active principles and enzymes remain intact and retains many of its properties after cooking. Ginger [30] has impressive anti-inflammatory and anti-viral properties because of the concentration of two compounds such as gingerols and zingerone, which inhibit the replication of viruses and penetrate healthy cells. You can take dry extract tablets or prepare an infusion with fresh ginger slices. Sage is an aromatic plant that has been traditionally used to treat viral infections. The anti-viral properties of sage are mainly attributed to compounds called safficinolides which are found in the leaves and stem of the plant. An infusion with $15 \mathrm{~g}$ of dried leaves per litre of water can be made. Fennel is a sweet-tasting plant that can fight certain viruses because of transanetol compound present in it. The leaves and flowers are consumed fresh, which can be chopped and added to salads. It is not recommended for children or pregnant women. Thyme ${ }^{29}$ herb is very useful to alleviate 
coughing. Echinacea is one of the most widely used plants in phytotherapy to stimulate immunity. It is recommended to take the flowers or the root, the most advisable is to resort to tablets and tinctures with standardized content. Licorice is one of the most recommended natural cures for fighting flu and pneumonia viruses. Vitamin D keeps the immune system in proper level as it helps our body to absorb calcium. Its level must also be maintained for immunity. Agood pre-biotic or pro-biotic is also must to keep our gut healthy. The healthier our gut, the stronger is our immune system. One can also have rice or beetroot kanji. Minerals like zinc and selenium should be included. They can be found in almonds, pumpkin seeds, sunflower seeds, unsalted cashew nuts and unsalted pistachios.Apart from all these dietary changes, a good mild to moderate body exercise of 30 minutes and proper sleep is also must to boost our immune system.

Preventive measures against Coronavirus

As there is no medicine/vaccine available for the CoVID-19 disease, it is advisable to take the following preventive measure to keep us fit and ready against any challenge from the disease. Washing our hands regularly

The soap is one of the simplest and most effective way of killing off any virus coming in contact. As per the United Nations International Children's Emergency Fund (UNICEF) suggestions, there should be proper frequent washing of hands because hands are the best fomites for virus . When we are unwell, unpleasant germs and pathogens that made us ill, will typically hide in our hands, nails, and between your fingers. That's why it is always advisable to wash our hands with any soap after using the bathroom, sneezing, coughing, touching animals and most importantly before eating.

The soap reduces the surface tension in water. Also due to the dual nature of two sided soap molecule, virus fat coating gets ripped out and demolishes it. However, this effect takes place in minimum 20 seconds. Therefore, while washing our hands we should be careful to clean areas between our fingers, behind palm and under nails and rub for at least 20 seconds, rinse and dry thoroughly. If the warm water is used with soap for washing the hand, it is further more effective.
Using hand sanitizer if soap is not available

In situations where we do not have access to soap and water, using alcohol-based hand sanitizer with at least $60 \%$ ethanol or $70 \%$ isopropanol is beneficial as per the recommendation of Centres for Disease Control and Prevention (CDC). Insufficient concentrations are not effective to disinfect. It is advised to always carry a small bottle of hand sanitizer so as use it at any time anywhere. However, it must be avoided to use hand sanitizers in excess as it can dry the hands as well. Also the excessive use of hand sanitizer may cause minor skin irritations. The symptoms like central nervous system depression, hypotension, hypothermia and decreased respiratory drive arising from isopropanol toxicity have also been reported ${ }^{31}$. Avoid touching our face with dirty hands

Viruses can enter our body through our eyes, nose, mouth and other orifices. Putting dirty, contaminated hands on our face can cause an infection. The germs should not be given any chance to enter our body.

Avoid close contact with sick people

It is obvious that if someone has an infection should stay away from close contact with others to avoid spreading the virus. Hugs, kisses and handshakes are to be totally avoided. If someone coughs and sneezes, walk away and explain that you don't want to get sick. Advise to stay at home and keep your friends and colleagues safe from whatever you have. You should also stay away from the visit to the crowded places. Maintaining a distance of one meter (social distancing) between yourself and anyone who is coughing or sneezing is also must to get rid of infection.

Wearing a surgical mask

Studies have shown that wearing a mask to protect against epidemics or respiratory disease may offer some protection but only in certain circumstances. But best of all, it is advisable to wear the mask while going outside or attending an infected person. As the saying goes: Better to prevent, than to cure. Remember to wear surgical mask and not regular ones, since surgical masks used by doctors are designed to prevent smallest of viruses entering the body, whereas normal masks can only prevent large dust particles. 
Covering our mouth while coughing or sneezing

While coughing and sneezing, the tiny droplets filled with thousands of viruses and bacteria travel at about 100 miles per hour. They can land on surfaces, on other people nearby, and even remain suspended in the air for long periods. It is therefore an effective way to stop spreading infection.

If possible, try coughing or sneezing into the bend of your elbow to help keep the droplets from escaping into the atmosphere. If it is not possible, covering the mouth with a disposable tissue while coughing or sneezing is the other alternative. However, the caution must be taken to discard it properly in the trash immediately and washing hands properly afterwards.

Cleaning and disinfecting the objects and surfaces

Kitchen and bathroom surfaces, telephone, mobile, door handles, staircase support and children's toys must be cleaned regularly using bleach or disinfectant. The bathroom and kitchen should also be cleaned and sanitized.

Cleaning vegetables and other things brought from the market

The vegetables, fruits and other grocery items brought from the market must be cleaned properly before use.

\section{Combat Stress}

It is no secret that any kind of stress is bad for our health and can make us more susceptible to viral infections. The chronic stress specially increases the chance of developing an infection after exposure to pathogens. So using yoga and relaxation techniques such as meditation or deep breathing to calm your mind is advised regularly. Drink plenty of water and limit alcohol consumption

It's best to keep ourselves hydrated by drinking plenty of water preferably warm water. Hydrated cells are better at fighting infections and removing toxins, germs and pollutants from our body.

\section{Get enough sleep}

Sleep helps our body to recover fast, reduces stress and is an essential survival mechanism to repair and heal. A sound sleep of minimum eight hours is essential for a healthy body.

\section{CONCLUSIONS}

To conclude, COVID-19 virus is a real devastating threat to the human life at present all over the world. The world is responding with unprecedented speed and mobilisation of their resources. The only prevention to get out of it is social distancing from individuals, proper and cautious sanitization, proper food intake full of antioxidants, vitamins, proteins, minerals in a balanced manner. It is advisable to drink a lot of lukewarm liquids of different combinations at regular intervals at least four to five times a day. The attempts are being made to invent the vaccine for the disease to save the mankind, however, there seems to no control at present and its prevention is only remedy. Therefore, the human lives can be saved by taking some precautionary measures as discussed above to keep us away from infection.

\section{ACKNOWLEDGMENTS}

None.

\section{CONFLICT OF INTEREST}

The authors declares that there is no conflict of interest.

\section{AUTHORS' CONTRIBUTION}

All authors listed have made a substantial, direct and intellectual contribution to the work, and approved it for publication.

\section{FUNDING}

None.

\section{ETHICS STATEMENT}

Not applicable.

\section{DATA AVAILABILITY}

All datasets generated or analyzed during this study are included in the manuscript and/or the Supplementary Files.

\section{REFERENCES}

1. Zhao Rond Lun, Liang Hu Qu. Animal -to-Human SARS-associated Coronavirus Emerg. Infect Dis. 2004;10(5):959-960. https://doi.org/10.3201/ eid1005.040022

2. C Huang, $Y$ Wang, $X \mathrm{Li}$, et al. Clinical features of patients infected with corona, Lancet. 2020;395:223497-506. https://doi.org/10.1016/S0140-6736(20)30183-5

3. Yang $\mathrm{H}$, Bartlam M, Rao Z. Drug design targeting the main protease, the Achilles' heel of coronaviruses Curr Pharm Des. 2006;12:4573-90. https://doi. org/10.2174/138161206779010369

4. Belouzard S, Millet JK, Licitra BN, Whittaker GR. 
Mechanisms of coronavirus cell entry mediated by the viral spike protein. Viruses. 2012;4:1011-33. https:// doi.org/10.3390/v4061011

5. Li W, Moore MJ, Vasilieva N, et al. Angiotensinconverting enzyme 2 is a functional receptor for the SARS coronavirus. Nature. 2003;426:450-454.

6. Mubarak A, Alturaiki W, Hemida MG. Middle East Respiratory Syndrome Coronavirus (MERS-CoV): Infection, Immunological Response, and Vaccine Development. J Immunol Res. 2019;6491738:1-11. https://doi.org/10.1155/2019/6491738

7. te Velthuis AJ, van den Worm SH, Snijder EJ. The SARScoronavirus $\mathrm{nsp} 7+\mathrm{nsp} 8$ complex is a unique multimeric RNA polymerase capable of both de novo initiation and primer extension. Nucleic Acids Res. 2012;40:1737-47. https://doi.org/10.1093/nar/gkr893

8. Stobart CC, Sexton NR, Munjal H, et al. Chimeric exchange of coronavirus nsp5 proteases (3CLpro) identifies common and divergent regulatory determinants of protease activity. J Virol. 2013;87:12611-8. https://doi.org/10.1128/JVI.0205013

9. Wang $\mathrm{H}$, Xue $\mathrm{S}$, Yang $\mathrm{H}$, Chen $\mathrm{C}$. Recent progress in the discovery of inhibitors targeting coronavirus proteases. Virol Sin. 2016;31:24-30. https://doi.org/10.1007/ s12250-015-3711-3

10. Egloff MP, Ferron F, Campanacci V, et al. The severe acute respiratory syndrome-coronavirus replicative protein nsp9 is a single-stranded RNA-binding subunit unique in the RNA virus world. Proc Natl Acad Sci. USA. 2004;101:3792-6. https://doi.org/10.1073/ pnas. 0307877101

11. Hu T, Chen C, Li H, et al. Structural basis for dimerization and RNA binding of avian infectious bronchitis virus nsp9. Protein Sci. 2017;26:1037-48. https://doi. org/10.1002/pro.3150

12. Bouvet $\mathrm{M}$, Lugari $\mathrm{A}$, Posthuma $\mathrm{CC}$, et al. Coronavirus Nsp10, a critical co-factor for activation of multiple replicative enzymes. J Biol Chem. 2014;289:25783-96. https://doi.org/10.1074/jbc.M114.577353

13. Narayanan K, Maeda A, Maeda J, Makino S. Characterization of the coronavirus $M$ protein and nucleocapsid interaction in infected cells. J Virol. 2000;74:8127-34. https://doi.org/10.1128/ JVI.74.17.8127-8134.2000

14. de Wit E, van Doremalen N, Falzarano D, Munster VJ. SARS and MERS: Recent insights into emerging coronaviruses. Nat Rev Microbiol. 2016;14:52334. https://doi.org/10.1128/JVI.74.17.8127-8134.2000

15. Nieto-Torres JL, Dediego ML, Alvarez E, et al. Subcellular location and topology of severe acute respiratory syndrome coronavirus envelope protein. Virology. 2011;415:69-82. https://doi.org/10.1016/j. virol.2011.03.029

16. Du L, He Y, Zhou Y, Liu S, Zheng BJ, Jiang S. The spike protein of SARS-CoV- A target for vaccine and therapeutic development. Nat Rev Microbiol. 2009;7:226-36. https://doi.org/10.1038/nrmicro2090

17. Chan KH, Malik Peiris JS, Lam SY, LLM Poon, KY Yuen, WH Seto. The Effect of temperature and relative humidity on the viability of SARS Coronavirus; Advances in Virol. 2011;734690. https:doi.org/10.1155/2011/734690. https://doi.org/10.1155/2011/734690

18. A. Lamarre, PJ Talbot. Effect of $\mathrm{pH}$ and temperature of the infectivity of Human Coronavirus 229E,Can. J. Microbiol. 1989;35(10):972-974. https://doi. org/10.1139/m89-160

19. LM Casanova, S Jeon, WA Rurala, DJ Weber, MD Sobsey. Effect of air temperature and relative humidity on coronavirus survival on surfaces Appl Environ Microbiol. 2010;76(9):2712. https://doi.org/10.1128/ AEM.02291-09

20. Africa Check. Coronavirus doesn't have own $\mathrm{pH}$ value alkaline food won't beat it, 2020, $25^{\text {th }}$ March.

21. ZH Yang, Y Huang, Lakshmanan Ganesh, et al. pHDependent Entry of Severe Acute Respiratory Syndrome Coronavirus Is Mediated by the Spike Glycoprotein and Enhanced by Dendritic Cell Transfer through DC-SIGN, J Virol. 2004;78(11):5642-50. https://doi.org/10.1128/ JVI.78.11.5642-5650.2004

22. J Liu, R Cao, M Xu, et al. Hydroxychloroquine, a less toxic derivative of chloroquine, is effective in inhibiting SARS-CoV-2 infection in vitro. Cell Discov. 2020;6:16. https://doi.org/10.1038/s41421-020-0156-0

23. News letter, Medical news today, 2020, $7^{\text {th }}$ May

24. Harshita C, Murthy kumar karthikeyan, Deepak Anupama, Dr. Dhanraj. Research Benefitial effects of olive oil on human health: A Review, Journal of Pharmacy and Technology. 2016;9(5):593-595. https:// doi.org/10.5958/0974-360X.2016.00112.8

25. Monika Gorzynik- Debicka, Paulina Przychodzen, Francesco Cappello, et al. Potential Health benefits of olive oil and plant polyphenols, Int J Mol Sci. 2018;19(3):686-690. https://doi.org/10.3390/ ijms19030686

26. H Jaladi, AM Nejad, AJ Ebadi, G Laey. Ethnobotany and folk pharmecutical properties of major trees or shrubs in north east of Iran, Asian J Chem. 2009;21(7):56325638.

27. ASM Nejad, M Bahmani, NA Shah, SA Shah, M Rafieian-Kopaei. Beliefs of herbal therapies of the community of the llam city of Ilam province, Iran. Journal of Pharmacy and Pharmacognosy Research. 2018;6(4):299-317.

28. Hercules Sakkas. Chrissanthy Papadopoulou, Antimicrobial Activity of Basil, Oregano, and Thyme Essential Oils. J. Micribiol Biotechnol. 2017;27(3):429438. https://doi.org/10.4014/jmb.1608.08024

29. Hazem S Elshafie, Ippolito Camele. An Overview of the Biological Effects of Some Mediterranean Essential Oils on Human Health. Bioactive Natural Products. 2017;9268468:1-14. https://doi. org/10.1155/2017/9268468

30. Chinedu Imo, Jivini Salvation Za'aku. Medicinal Properties of Ginger and Garlic: A Review, Curr Trends Biomedical Eng \& Biosci. 2019;47-52.

31. DL Stevens, Meri Hix. Intentional ingestion of hand sanitizer in an adult psychiatric unit. Ment Health Clin. 2020;10(2):60-63. https://doi.org/10.9740/ mhc.2020.03.060

32. M Prajapati, P Sharma, N Shekar, et al. Drug Targets for corona virus: A Systematic Review, Indian J Pharmacol. 2020;52:56-65. https://doi.org/10.4103/ ijp.IJP_115_20 